\title{
Antioxidant Activities of Imino Chromene Derivatives with Even Alkyl tail: Synthesis and Characterisation
}

\author{
Madasamy Kumar, Veerappan Jeyachandran, Arumugam Sathamraja, Pandian Paulraj'
}

\begin{abstract}
The reaction between substituted 4-hydroxybenzaldehyde, active methylene compounds iminochromene derivatives. Structures of the sewere established upon the basis of IR,1HNMR,13CNMR, and MASS data. Invitro, antioxidants activities oft hese compounds against superoxide anion radical, nitric oxide radical, DPPH radical and hydrogen peroxide were evaluated and compared with standard natural antioxidants ascorbicacid.
\end{abstract}

Keywords: chromenes, imines, amines, antioxidants

\section{INTRODUCTION}

Multicomponent reactions (MCRS) are reactions where numerous reactants involved in single synthetic operation and give new compounds.1 This type of reactions avoids purification process and often wide variety of complex molecule in a single step, inturn it is very useful for saving solvent and reagents. Among many heterocyclic compounds, chromenes are very important due to its biological activity such as antioxidants, 2 anticancer,anti-microbial, 3 anti-inflammatory,4 anti-HIV,5 and anti-tumor,6,7alzimer disease, 8,9antihypotensive10and antileishmanial.9 There are many reports shown that synthesis of different chromene derivatives and its applications (Figure 1).11, 12, $13 \mathrm{~A}$ Knoevenagel condensation is the reaction between salicylaldehyde with active methylene compounds followed by intramolecular cyclisation to give imino derivatives. 14 As per reports, different products are obtained by control of a solvent, 15 ratio of reagents and temperature16etc., Due to importance of these chromene derivatives, numerous green approaches 17 have been developed under distinct conditions like thermal heating,18 microwave, ultrasonic, electrochemical, infrared, and solvent free conditions. We could not find many reports on variation of an alkyl side chain to see the effect on antioxidant properties of chromene derivatives. So we are motivated to synthesis imino and amino chromenes by taking alkylated aldehyde and malonitrile. Currently, many investigations are going on effect of free radicals in biological systems such as lipids, DNA and protein, also create many diseases like atherosclerosis, neurodegenerative disease, rheumatoid arthritis, age related disease, cancer initiation and tumor.19, 20, 21 It is necessary to keep a proper level of natural antioxidant such as vitamin E, $\mathrm{C}$ and glutathione in a biological system in order to avoid serious health problems.22, 23, 24 All these health problems are caused by action of free radical oxygen (ROS) and reactive nitrogen (RNS) species, commonly known as (RSs).25, 26.[1]-[7]

\section{EXPERIMENTAL METHOD AND TECHNIQUES}

\section{Experimental}

All NMR spectra were recorded using Bruker $(300 \mathrm{MHz})$ spectrometer. JASCO-FTIR spectrometer $\left(4000-400 \mathrm{~cm}^{-1}\right)$ used for recording Infrared spectra. Electro spray ionization mass spectrometry (ESI-MS) analysis was performed in the negative ion mode on a liquid chromatography-ion trap mass spectrometer (LCQ Fleet, Thermo Fisher Instruments Limited,US).The DPPH radical scavenging action of the compounds was dignified rendering to the method of Blios. ${ }^{20}$ The assay of nitricoxide (NO), $\mathrm{H}_{2} \mathrm{O}_{2}, \quad\left(\mathrm{O}_{2}{ }^{-}\right)$ scavenging activity was determined using the method available in literature.

\section{RESUlTS AND DISCUSSION}

\section{A. Antioxidant activities}

In the present study, antioxidant potential of synthesized 3-cyano-2-imino-2H-chromen-7-yl 4-(alkyloxy)benzoate (6a-h) were studied using $\mathrm{DPPH}, \mathrm{NO}^{*}, \mathrm{O}_{2}^{-{ }^{-}}, \mathrm{H}_{2} \mathrm{O}_{2}$ radical scavenging [8]-15]

\footnotetext{
Revised Manuscript Received on December 30, 2019.

Madasamy Kumar Associate Professor Department Of Science \& Humanities, Barath Institution Of Higher Education And Research,TamilNadu,India.Email:kmrorg@gmail.com

VeerappanJeyachandran, Associate Professor Department Of Science \& Humanities, Bharath Institution Of Higher Education And Research TamilNadu,India.Email: jeyorg@gmail.com

ArumugamSathamraja Department Of Science \& Humanities, Bharath Institution Of Higher Education And Research TamilNadu,India.Email: sathamrajaarumugam@gmail.com

PandianPaulraj,Associate Professor Department Of Science \& Humanities, Bharath Institution Of Higher Education And Research TamilNadu,India.Email: paulrajp.che@ bharathuniv.ac.in
} 
Table II. Antioxidant activity of chromene derivatives (6a-h)

\begin{tabular}{llcccc}
\hline \multicolumn{5}{c}{ IC $_{50}(\mu \mathrm{M})$} \\
\hline SNo & Entry & DPPH & NO' $^{*}$ & $\mathbf{O}_{2^{-*}}$ & $\mathbf{H}_{2} \mathbf{O}_{2}$ \\
\hline 1 & Vitamin C & $32.52 \pm 0.11$ & $55.00 \pm 0.12$ & $52.00 \pm 0.56$ & $43.00 \pm 0.65$ \\
2 & $6 \mathrm{a}$ & $27.16 \pm 0.41$ & $22.48 \pm 0.41$ & $35.04 \pm 0.49$ & $42.48 \pm 0.82$ \\
3 & $6 \mathrm{~b}$ & $27.95 \pm 0.32$ & $24.62 \pm 0.03$ & $31.96 \pm 0.38$ & $35.67 \pm 0.15$ \\
4 & $6 \mathrm{c}$ & $27.93 \pm 0.36$ & $27.72 \pm 0.36$ & $31.08 \pm 0.40$ & $34.88 \pm 0.38$ \\
5 & $6 \mathrm{~d}$ & $28.75 \pm 0.18$ & $27.37 \pm 0.92$ & $28.90 \pm 0.11$ & $33.17 \pm 0.54$ \\
6 & $6 \mathrm{e}$ & $28.11 \pm 0.22$ & $27.23 \pm 0.23$ & $30.83 \pm 0.92$ & $33.15 \pm 0.45$ \\
7 & $6 \mathrm{f}$ & $30.65 \pm 0.38$ & $27.28 \pm 0.53$ & $29.76 \pm 0.36$ & $29.76 \pm 0.43$ \\
8 & $6 \mathrm{~g}$ & $31.04 \pm 0.58$ & $29.13 \pm 0.35$ & $28.48 \pm 0.53$ & $30.60 \pm 0.82$ \\
9 & $6 \mathrm{~h}$ & $31.04 \pm 0.45$ & $33.72 \pm 0.18$ & $27.96 \pm 0.13$ & $26.89 \pm 0.22$ \\
\hline
\end{tabular}

technique by spectrophotometrically. Radical scavenging activities of all derivatives were determined from the interacting ability of derivatives with $\mathrm{DPPH}, \mathrm{NO}^{\circ}, \mathrm{O}_{2}{ }^{-}, \mathrm{H}_{2} \mathrm{O}_{2}$ radicals. The antioxidant activities were expressed as $50 \%$ inhibitory concentration values in Table 2,

Figure 2, and compared with that of standard ascorbic acid. The hydrogen donating ability of amines and imine groups present as part of all synthesized derivatives in the series $5 \mathrm{a}-\mathrm{h}$ LowerIC ${ }_{50}$ valuegivesbetterradical-scavengingactivity.Fromt hetable,it was clear that almost all the compounds were shownradicalscavengingactivitiesinDPPH'assay.Itwasimport anttonotethat6a,6band6c[16]-[22]

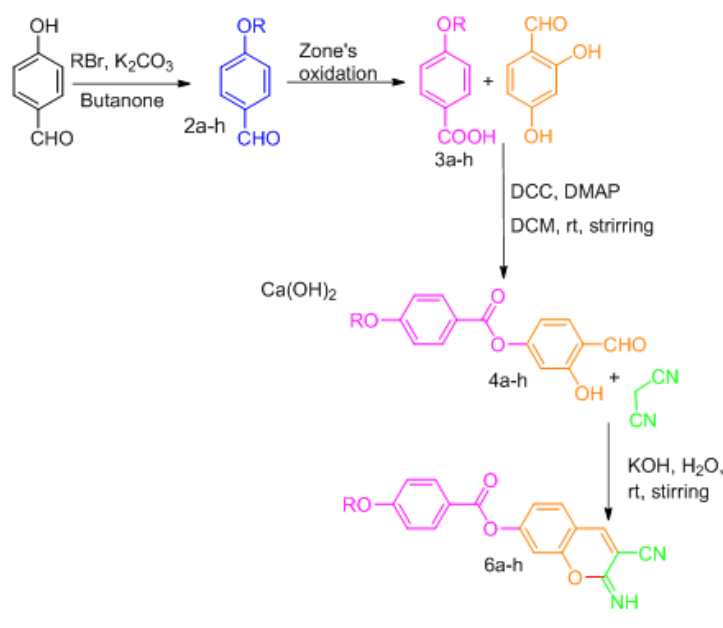

$\mathrm{R}=\mathrm{C}_{5} \mathrm{H}_{11}, \mathrm{C}_{6} \mathrm{H}_{13}, \mathrm{C}_{7} \mathrm{H}_{15}, \mathrm{C}_{8} \mathrm{H}_{17}, \mathrm{C}_{10} \mathrm{H}_{21}, \mathrm{C}_{12} \mathrm{H}_{25}, \mathrm{C}_{14} \mathrm{H}_{29}, \mathrm{C}_{16} \mathrm{H}_{33}$

\section{FIG 1 1. Synthetic procedures for series5 and 6}

Shown better DPPH scavenging activity than vitamin withIC ${ }_{50}$ values27.16,27.95and27.93 $\mu$ Mrespectively.TheDPP $\mathrm{H}^{\circ}$ activities of tested were found to be in the decreasing order of $6 \mathbf{a}, 6 \mathbf{c}, 6 \mathbf{b}, 6 \mathbf{6}, 6 \mathbf{d}, 6 \mathbf{6}, \mathbf{6 g}$ and $6 \mathbf{h}$. We can find in case of NO'radical scavenging activities, compound $6 \mathrm{a}$ and $6 \mathrm{~b}$ have very low IC50 values are 22.48 and $24.52 \mu \mathrm{M}$ respectively. The decreasing orders of antioxidant activity of these compounds were $6 \mathrm{a}, 6 \mathrm{~b}, 6 \mathrm{e}, 6 \mathrm{~d}, 6 \mathrm{c}, 6 \mathrm{f}, 6 \mathrm{~g}$ and $6 \mathrm{~h}$. The results of the $\mathrm{NO}^{\circ}$ assay were expressed as $\mathrm{IC}_{50}$ values in Table 2 revealed that $\mathbf{6 h , 6 g}$ showed better super oxide radical scavenging activity than natural antioxidant vitamin withIC $_{50}$ of 27.96 , and $28.48 \mu \mathrm{M}$ respectively. Surprisingly, $\mathrm{IC}_{50}$ values of all synthesized derivatives were lower thanIC ${ }_{50}$ VitaminC.Thesuperoxide anion radical scavenging and $6 \mathrm{a}-\mathrm{h}$ might be responsible for their antioxidant properties.

activities of tested was found to be in the decreasing order of 6h, 6g,6d,6f,6e,6c,6b,6aandVitaminC. The hydrogen peroxide radical scavenging activities of tested wasf ound to be in the decreasing order of 6h,6f,6g,6e,6d,6c,6b,6aandVitaminC.

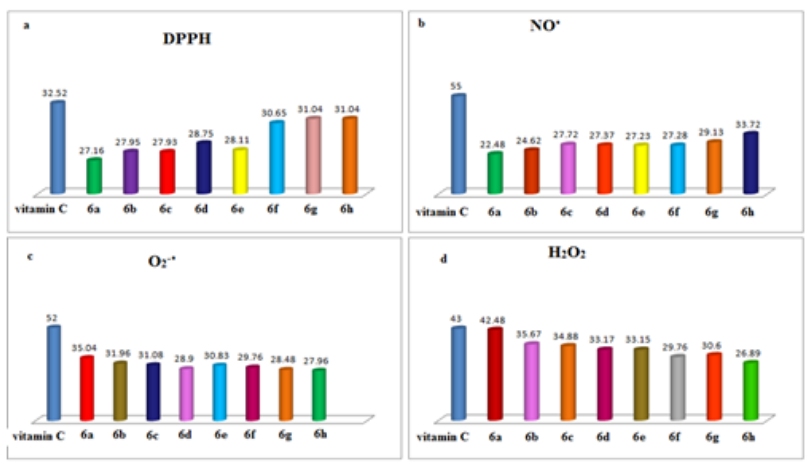

Fig.2.Antioxidant activity of $6 \mathrm{a}-\mathrm{h}$ in $\mathrm{IC}_{50}$ values

\section{Conclusion}

A series of 3-cyano-2-imino-2H-chromen-7-yl 4-(alkyloxy) benzoate have been synthesized. The structures were confirmed by ${ }^{1} \mathrm{H}-\mathrm{NMR},{ }^{13} \mathrm{C}-\mathrm{NMR}$, FT-IR and mass spectroscopic techniques. The compounds exhibited excellent radical scavenging activities against super oxide anion radical, nitric oxide radical, DPPH radical and hydrogen peroxide. Among all the derivatives $6 \mathrm{a}, 6 \mathrm{c}(\mathrm{DPPH}), 6 \mathrm{a}, 6 \mathrm{~b}$ (NO $), 6 \mathrm{~g}, 6 \mathrm{~h}\left(\mathrm{O}_{2}^{-*}\right)$, 6h, 6f $\left(\mathrm{H}_{2} \mathrm{O}_{2}\right)$ having better free radical scavenging ability. Based on the result, it is clear that these can be used as good antioxidant in the field of medicinal and food industry.

\section{REFERENCES}

1. Elinson M N, Ilovaisky A I, Merkulova V M, Belyakov P A, Chizhov A OandNikishin G I 2010 Tetrahedron. 664043

2. Singh O M, Devi N S, Thokchom D S and Sharma G J, 2010 Eur.J. ofMedi. Chem., 452250

3. KumarM, SribalanR, andPadmini* V, Chemistry Select, 2016, 1 , 1 6.

4. P. Paulraj, N. Janaki, S. Sandhya, K. Pandian, Colloids and Surfaces A: Physicochem. Eng. Aspects 377 (2011) 28-34.

5. Khan K M, Ambreen N, Mughal U R, Jalil S, Perveen S and Choudhary M I2010Eur.J. ofMedi. Chem., 454058

6. R. Marx Nirmal, P. Paulraj, K. Pandian, K. Sivakumar, AIP Conf. Proc. 1391 (2011) 597-599.

7. E. Prabakaran, S. Parani, M. Alexander, P. Paulraj, K. Pandian, J. Nanosci. Lett. 3 (2013) 18(1-9).

8. Charles Johannes W, Michael S, Visser S, Weatherhead G and Hoveyda A H 1998J. Am. Chem. Soc., 1208340

9. KumarM, PadminiV*, PonnuvelK, J.Saudi Chem. Soc,(2014):http://dx.doi.org/10.1016/j.jscs.2014.03.006

10. Brühlmann C, Ooms F, Carrupt PA, Testa B, Catto M, Leonetti F, Altomare C and Carotti A 2001J. Med. Chem., 443195

11. Isabel M, Bachiller F, Pérez C, Monjas L, Rademann J and Franco M I R 2012. J. Med. Chem., 551303

12. Kumar M, PadminiV*, BhuvaneshN, Res. Chem. Intermediates., 2017, 8, 4517-4530.

13. Tatiana A D and Proença M F, 2012TetrahedronLett. 535235

14. Areias F, Costa M, Castro M, Brea J, Gregori-Puigjané E, Proença M F, Mestres J and Loza MI2012 Eur.J. ofMedi. Chem. 54303

15. K. Kaviyarasu, E. Manikandan, P. Paulraj, S.B. Mohamed, J. Kennedy, Journal of Alloys and Compounds 593 (2014) 67-70. 
16. P. Paulraj, A. Manikandan, E. Manikandan, K. Pandian, M. K. Moodley, K. Roro, and K. Murugan, J. Nanosci. Nanotechnol., 18 (2018) 3991-3999.

17. Aust S D, Chignell C F, Bray T M, Kalyanaraman B and Mason R P, 1993Toxicol. Appl. Pharm. 120168

18. P. Bhavani, A. Manikandan, P. Paulraj, A. Dinesh, M. Durka, S. Arul Antony, J. Nanosci. Nanotech. 18 (2017) 4072-4081.

19. PonnuvelK, Kumar M, PadminiV*, Sensors and Actuators B: chemical, 2016, 227, 242-247.

20. Halliwell B and Gutteridge J M C 1999Free Radicals in Biology and Medicine, 3rd ed., Oxford University Pressp246-350

21. Gulcin I, Mshvildadze A and Gepdiremen E RPhytotherappyResearch20 130

22. Oktay M, Gulcin I and Kufrevioglu O I Lebensm.WissTechol. 36263

23. FreiB1994Natural antioxidants in Human Health and Disease; San Diego, Academic Press p157-197

24. Halliwell B and Gutteridge J M C1990Method Enzymology1861

25. Barros L, Ferreira M J, Queiros B, Ferreira I C F R, and Baptista P2007 Food Chem. 103413

26. Blios M S 1958Nature 181199

27. Green L C, Wagner D A, Glogowski J, Skipper P L, Wishnok J S and Tannenbaum S R 1982 Anal. Bio.Chem. 126131

28. Ruch R J, Cheng S J and Klaunig J E 1989 Carcinogenisis 10,1003.

29. Beauchamp C and Fridovich I1971Analytical Biochemistry 44276

30. Majumdar K C, Chakravorty S, Pal N and Sinha R K 2009 Tetrahedron 657998

\section{AUTHORS PROFILE}

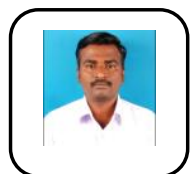

Madasamy Kumar Associate Professor Department Of Science \& Humanities, Bharath Institution Of Higher Education And Research,TamilNadu,India.Email:kmrorg@gmail.com

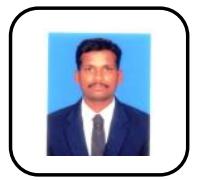

Veerappan Jeyachandran, Associate Professo Department Of Science \& Humanities, Bharath Institution Of Higher Education And Research TamilNadu,India.Email: jeyorg@gmail.com

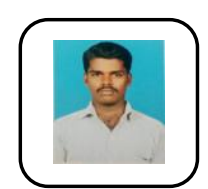

Arumugam Sathamraja lab instructor Department Of Science \& Humanities, Bharath Institution Of Higher Education And ResearTamilNadu,India.Email: sathamrajaarumugam@gmail.com

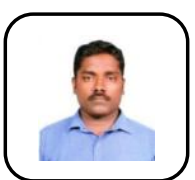

Pandian Paulraj, Associate Professor Department Of Science \& Humanities, BharathInstitution Of Higher Education And Research TamilNadu,India.Email: paulrajp.che@bharathuniv.ac.in 